\title{
LETTERS
}

\section{Excluding pregnancy from COVID-19 trials: Protection from harm or the harm of protection?}

We agree with Cheng and colleagues regarding the need to generate robust evidence through randomized trials. ${ }^{1}$ However, we note that inclusion of pregnant individuals is conspicuously absent from this call to action. Of investigations related to coronavirus disease 2019 (COVID-19) registered on clinicaltrials. gov, 28/1486 (1.9\%) include pregnancy and $4 / 28$ involve pharmacologic interventions. This grants pregnant individuals access to a mere $0.3 \%$ of all COVID-19related intervention trials. ${ }^{2}$

Exclusion of pregnant individuals from trials originated from the perspective of beneficence and protection of the vulnerable, ${ }^{3}$ a safeguard predicated on the obsolete assumption of incapacity to provide informed consent. This practice now directly contravenes the right to autonomy and self-determination. ${ }^{3}$

The Global Forum on Bioethics in Research denounced the classification of pregnant individuals as vulnerable, given absence of evidence that the pregnant state confers cognitive impairment or invokes undue susceptibility to harm. ${ }^{4}$ Omitting pregnant individuals from the controlled research environment magnifies vulnerability by shifting experimentation onto the clinical stage, ${ }^{4}$ where interventions necessary for preservation of maternal and fetal health are instituted in absence of trial data, robbing this population of access to a platform accepted as the gold standard of evidence-based medicine.

The Government of Canada called for consideration of inclusion of pregnant individuals in trials. ${ }^{5}$ Spurred by lessons from the Ebola outbreak, which restricted pregnant individuals from trials with any degree of reproductive toxicity and outright barred them from vaccine trials, the Global Forum on Bioethics in Research emphasized the imperative need for a plan to include pregnancy data ahead of the next epidemic. ${ }^{4}$ Sadly, we find ourselves repeating past mistakes.

Until inclusion in trials is mandated, pregnant individuals and their offspring will continue to be subjected to inappropriate and harmful "safeguarding of vulnerabilities," erosion of individual autonomy and direct harms brought about by use of pharmacologics that have not been subjected to the gold-standard investigation available to the rest of the population. The status quo represents nothing less than a violation of equity and human rights and should be challenged now.

\section{Ann Kinga Malinowski MD MSc}

Maternal-fetal medicine specialist, Mount Sinai Hospital (Sinai Health System), University of Toronto, Toronto, Ont.

\section{John Snelgrove MD MSc}

Maternal-fetal medicine physician, Mount Sinai Hospital (Sinai Health System), University of Toronto, Toronto, Ont.

\section{Nan Okun MD MHSc}

Maternal-fetal medicine physician, Mount Sinai Hospital (Sinai Health System), University of Toronto, Toronto, Ont.

Cite as: CMAJ 2020 June 8;192:E634. doi: $10.1503 / \mathrm{cmaj} .75807$

\section{References}

1. Cheng MP, Lee TC, Tan DHS, et al. Generating randomized trial evidence to optimize treatment in the COVID-19 pandemic. CMAJ 2020;192:E405-7.

2. ClinicalTrials.gov. 31 Studies found for: pregnancy, COVID. Available: https://clinicaltrials.gov/ct2/ results? cond=COVID\&term=pregnancy \&cntry= \&state=\&city=\&dist=\&Search=Search (accessed 202014 May).

3. Park SS, Grayson MH. Clinical research: protection of the "vulnerable"? J Allergy Clin Immunol 2008; 121:1103-7.

4. Ethics of research in pregnancy, Buenos Aires, Argentina, 3 and 4 November 2016 [meeting report]. Global Forum on Bioethics Research; 2017. Available: www.gfbr.global/wp-content/uploads/ 2017/04/GFBR-2016-report-ethics-of-research-in -pregnancy-FINAL.pdf (accessed 2020 Apr. 25).

5. Considerations for inclusion of women in clinical trials and analysis of sex differences [guidance document]. Ottawa: Health Canada; 2013, updated 2013, Dec. 10. Available: www.canada.ca/ en/health-canada/services/drugs-health-products/ drug-products/applications-submissions/guidance -documents/clinical-trials/considerations-inclusion -women-clinical-trials-analysis-data-sex-differences. html.

Competing interests: None declared. 